\title{
A MINIATURE NEEDLE-HOLDER FOR THE FINEST SUTURING*
}

BY

\author{
V. C. RAMBO \\ Christian Medical College, Ludhiana, East Punjab, India
}

MANY needle-holders are in use and each surgeon has his own preferences for different kinds of suturing, in different kinds of tissues, and in different positions of the surgical field. The position presents a difficult problem and there is often a need for greater accuracy and manoeuverability than is possible with the conventional needle-holders.

To meet the need for such an instrument, a "Holder Needle" has been developed and reported (Rambo, 1962). A small needle-holder has also been developed for me by John and Ernst Grieshaber. This holder is $4.5 \mathrm{~cm}$. long and $2 \mathrm{~cm}$. in height at the handle. It can be held between the index finger and the thumb for the finest sewing of tissues such as the cornea and sclera, and would also be useful in suturing nerves and vessels (Figs 1 and 2).

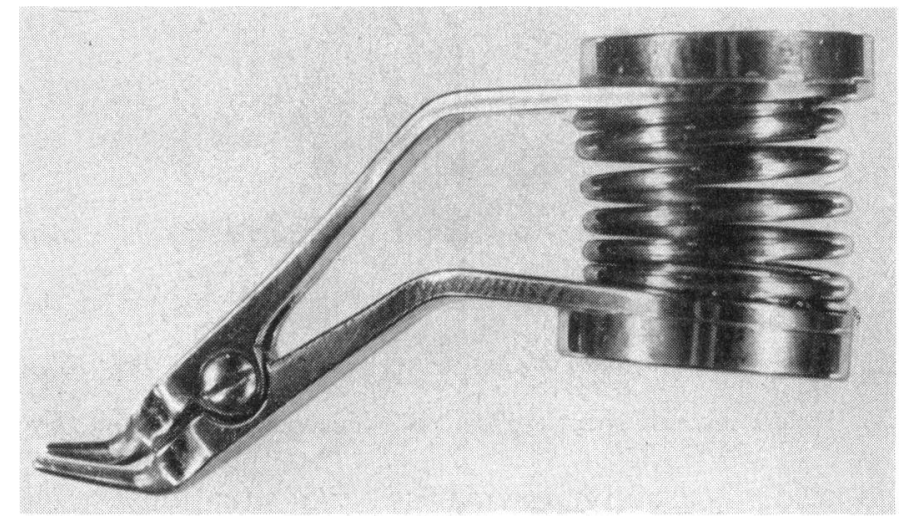

FIG. 1.-Side view of needle-holder.

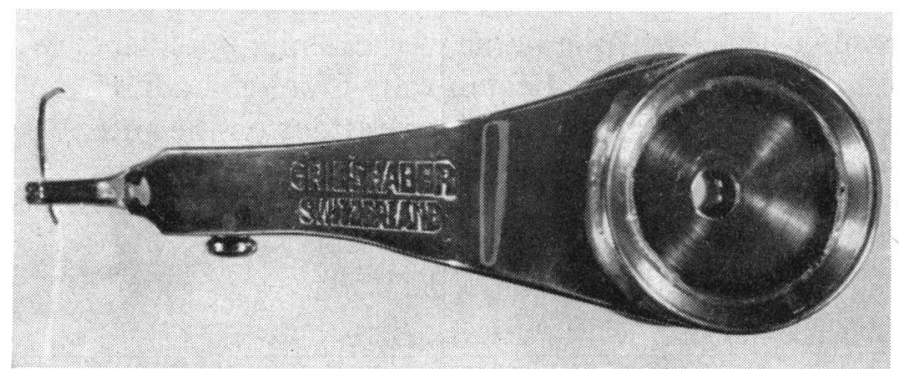

Fig. 2.-Needle-holder viewed from above.

* Received for publication February 20, 1962. 
The placing the tip of a fine needle is much more exact with this instrument than with any holder requiring the gross use of the wrist and the movement of the whole hand.

Though this needle-holder incorporates a new principle, it requires very little practice to develop skill and speed in use. The jaws are opened by compressing the handles and are closed by releasing the pressure, thus allowing the strong spring located between the handles to hold the needle with sufficient strength for all ordinary sewing. It goes without saying that the needle used should be sharp, and that the surgeon should wear spectacles giving sufficient magnification for perfect vision. Slightly curved needles are easier to handle than those with a full curve. The needle-holder can be held in any position, with the needle directed to the right or left, and is so small that it can fit into almost any area desired. There is no click or jerk of the instrument on grasping or on release, and the degree of pressure needed to open the jaws is no greater than the finger strength normally required for surgery.

This instrument does not completely replace the conventional needleholders, but I am delighted with its usefulness in finer suturing.

\section{REFERENCE}

Rambo, V. C. (1962). Brit. J. Ophthal., 46, 184.

\section{CORRESPONDENCE}

\section{VITREOUS HAEMORRHAGE AFTER "ROVACICLINA"}

To the Editorial Committee of the British Journal of OpHThalmologY

SIRs,-I should like to point out to your readers that, following the indications contained in an article by J. B. Chodos and H. E. Habegger-Chodos, entitled "The Treatment of Ocular Toxoplasmosis with Spiramycin", which appeared in the Archives of Ophthalmology (1961) 65, 401, I have used "Rovaciclina" (a combination of Spiramycin, a phosphate complex of tetracycline, and several vitamins) in cases of toxoplasmosis and also as a general antibiotic. Now, in the months of April and May, 1962, I have seen three cases of haemorrhage into the vitreous, an occurrence which was not repeated when this antibiotic was replaced by others which I have used for some years, according to the data from the literature.

The three cases had no dangerous sequelae, for the blood was reabsorbed after an interval of 2 or 3 months leaving thin bands of organisation in the vitreous.

Yours faithfully,

São Paulo,

A. Busacca.

BraZIL.

August 13, 1962. 